\title{
The Most and Least Frequent Vocabulary Learning Strategies of High School English Language Learners
}

\author{
Jean Kaya (Corresponding author) \\ Department of Linguistics, Southern Illinois University \\ 1000 Faner Drive, Carbondale 62901, Illinois, United States \\ Tel: 1-618-559-8934Ｅ-mail: johnlackroom@yahoo.fr \\ Krassimira Charkova \\ Dr., Senior Lecturer, College of Liberal Arts, Southern Illinois University \\ 1000 Faner Drive, Carbondale 62901, Illinois, United States \\ Tel: 1-618-453-3425Ｅ-mail: sharkova@siu.edu
}

Received: July 1, 2014 Accepted: July 18, 2014 Published: July 23, 2014

doi:10.5296/ijele.v2i2.6019 URL: http://dx.doi.org/10.5296/ijele.v2i2.6019

\begin{abstract}
This study emphasized the most and least frequent vocabulary learning strategies that English language teachers encourage students to use, and the strategies that students actually use to build their vocabulary. Finding out whether the students' most used strategies were teacher-encouraged or independently-learned was another point of interest. The participants included 20 male and 23 female learners of English of ages 18 to 22, all of them students in the Arts program at a Southern Congolese high school. They completed a Likert-scale questionnaire of 34 statements and four short-answer questions. Statistical and content analysis methods were employed. The study revealed contextual guessing and dictionary use to be the most frequently encouraged and used strategies, whereas pronunciation and flashcards were the least frequently encouraged and used. These strategies showed no significant difference between the teacher-encouraged and the student-used strategies, which provided evidence about the important role that language teachers play in students' learning in general, and in strategy in particular. Furthermore, the majority of participants attributed their frequently-used strategies to their teachers' practices and advice. Further discussion stresses the potential reasons why pronunciation receives less attention.
\end{abstract}

Keywords: Congolese EFL learners, vocabulary strategies, contextual guessing, dictionary, pronunciation 


\section{Introduction}

Penha (2006) points out that no reading, writing, speaking, listening, or literature-based activity discussion can be conducted with learners without providing them with the conventional vocabulary to perform the activity. It consequently goes without saying that vocabulary building is one of the most important aspects of learning a second language, and words may therefore be considered as the foundation stones and building blocks of any language. For this reason, building learners' vocabulary knowledge is critical to the overall language development. Because all language skills are dependent upon vocabulary (Nation, 1990; Pehna, 2006), teaching vocabulary and vocabulary learning strategies becomes a must. Nirattisai and Chiramanee (2014) invite language teachers to heed vocabulary learning strategies and the importance of the strategies in order to encourage students to use these strategies because "the use of vocabulary learning strategies can lead students to large vocabulary size" (Nirattisai \& Chiramanee, 2014, p. 284).

Oxford and Scarcella (1994) posited that if we expect students to enhance their vocabulary, it is important to explicitly teach them vocabulary learning strategies. Likewise, Ghazal (2007) mentioned that one way to lessen the burden of foreign language learners' challenges is to assist them by teaching them how to apply vocabulary learning strategies. Contextual guessing and dictionary use for example are two of the strategies that have been emphasized by a number of researchers (Bensoussan, Sim, \& Weiss, 1984; Huang \& Eslami, 2013; Ibrahim, 2012; Lawson \& Hogben, 1996; Mokhtar, Rawian, \& Fauzee, 2013; Prichard, 2008; Sultana, 2014) in order to examine the vocabulary learning strategies of English as second or foreign language learners. The present paper emphasized the frequencies of encouragement by teachers and the frequencies of use by learners of contextual guessing, dictionary, pronunciation, and flashcards as vocabulary learning strategies for high school English language learners.

\section{Literature Review}

The present study has been designed in view of the findings of previous studies which are reviewed in this section. The review has been organized into five subsections. Subsection one looks at studies which have examined the effect of instruction on second language vocabulary learning strategies. It also includes studies on the frequencies of use and/or effectiveness of vocabulary learning strategies by second language learners. Subsection two reviews studies that have concentrated on dictionary use. Subsection three emphasizes studies on contextual guessing. Subsection four deals with studies on pronunciation, and the last subsection stresses studies on flashcards use.

\subsection{Studies on the Effect of Instruction and the Frequencies of Use or Effectiveness of Strategies}

Since the 1980s, research on vocabulary learning strategies has started to gather momentum, thus recognizing their important role in the acquisition of second language lexical knowledge. Explicit instruction has a positive impact on students' vocabulary acquisition, and it contributes to the development of students' metacognitive awareness (Bornay, 2011). 
Bornay's (2011) study revealed that most participants $(87.5 \% ; \mathrm{N}=16)$ found explicit instruction strategy helpful and useful. Oxford and Scarcella (1994) also stressed the importance of explicitly teaching vocabulary and vocabulary learning strategies. However, they point out that such instruction is advantageous mostly for adult learners. Some words can actually be learnt incidentally while other words require more attention and effort (Hulstijn, 1989). It is with such words and phrases that appropriate vocabulary learning strategies should be employed.

Fan (2003) examined the relationship among frequency of use, perceived usefulness, and actual usefulness of second language vocabulary learning strategies of Cantonese students about their English vocabulary learning. The study revealed that although vocabulary learning strategies were considered useful by students, they only used them occasionally with a low frequency.

\subsection{Studies on Dictionary Use}

Though research has demonstrated that dictionary use while reading often results in spending twice the time that would be spent if the use of dictionaries was prohibited to complete the same reading assignment (Luppescu \& Day, 1993), it has also been revealed that using a dictionary has a significant effect on students' performance on a vocabulary test. EFL students' use of a dictionary while reading can facilitate the learning of vocabulary (Luppescu \& Day, 1993). Luppescu and Day (1993) reveal that learners who are given the opportunity to consult either a dictionary or another individual for the meaning of unfamiliar words in a text can perform better than those who have neither. Dictionary use can furthermore increase learners' confidence in the development of their vocabulary knowledge as it gives them the possibility to either check the previously guessed words and possibly retain the correct meaning (Nation, 1990) or look up the words which are targeted to be independently learned.

These findings differ to some extent from those reported in Bensoussan, Sim, and Weiss (1984) which showed that the use of dictionaries for either independent reading comprehension or reading comprehension for test-taking purposes had no significant effect on either passage comprehension or reading comprehension score.

Regardless of the format (online or printed) of dictionaries however, different trends have been revealed regarding the preferences of dictionaries. The monolingual dictionary was preferred by the participants of the study conducted by Al-Shuwairekh (2001), whereas participants in different studies posited the bilingual dictionary (Bensoussan, Sim, \& Weiss, 1984; Ibrahim, 2012; Yu, 2000).

\subsection{Studies on Contextual Guessing}

When learners have built some basic vocabulary, it becomes the standing point of the learners' skills, mostly their reading skills as they can clearly see the words and guess or infer unknown word meanings from context. Nation (1990) mentions that most words can be guessed from context. Guessing may additionally depend on the learner's ability to make inferences or analyze words from his general language knowledge - by thinking about synonyms, antonyms, or provided examples - or parts of the words through the word's root or 
affixes (Fuentes, 1976; Lawson \& Hogben, 1996; Nation, 1990; Oxford \& Scarcella, 1994). Guessing alone is, however, sometimes considered to be unreliable (Huang \& Eslami, 2013; Kaivanpanah \& Alavi, 2008; Nation, 1990). Nevertheless, learners might prefer guessing than using other strategies as they may argue that creating a pause to check a word meaning from a dictionary for instance would waste time and lower the motivation to read by blocking the reading flow. Guessing plays a crucial role in comprehension since once the learner has understood the passage from potential cues, he might not need to seek the meaning of every single word of the passage.

\subsection{Studies on Pronunciation}

Pronunciation is one of the important factors that facilitate communication between interlocutors. Regardless of other language errors, a speaker with good pronunciation becomes intelligible (Fraser, 2000). However, pronunciation is one among the language areas where foreign language learners face more difficulties (Gilakjani, 2012; Wu, 2014). To help learners enhance their pronunciation, it has been observed that many dictionaries and books include phonetics or other helpful pronunciation symbols. The standardized English language tests like the Test of English as a Foreign Language (TOEFL) and the International English Language Testing System (IELTS) also include the pronunciation construct in the assessment of the speaking skill.

Second or foreign language teachers, however, give little attention to pronunciation teaching in classrooms (Gilakjani, 2011; Tergujeff, 2013). A number of English language teachers who engage in teaching pronunciation often find themselves less equipped to complete their task (Fraser, 2000). Other language teachers or institution curricula limit themselves to introducing the alphabet of second languages and fail to further focus on pronunciation (Gilakjani, 2011). The necessity to teach pronunciation in EFL/ESL classrooms is unquestionable since good pronunciation creates the speaker's self-confidence and intelligibility in the addresser-addressee interactions (Fraser, 2000; Gilakjina, 2011).

\subsection{Studies on Flashcards Use}

Regardless of whether it is a native, second, or foreign language, language learners often use flashcards to either learn new words or test themselves (Kornell, 2009) regarding the retention of new or difficult words. Oxford and Crookall's (1990) study revealed flashcards use as one of the most widely-used vocabulary learning strategies. Flashcards are also commonly used for preparation by takers of standardized tests such as the Graduate Record Examination (GRE) (Kornell, 2009) and the Test of English as a Foreign Language (TOEFL).

From these standardized tests it can consequently be extrapolated that flashcards are used not only by low-level learners of English as a second or foreign language but also by advanced-level ESL/EFL learners as well as native speakers of English even at the university level. By definition, the GRE test is a Graduate school entrance examination. The TOEFL test is likewise for non-native speakers of English seeking admission to graduate schools in countries like the United States of America, Canada, and Australia where English is a native language. Al-Shuwairekh (2001) concluded that using flashcards is an effective strategy for 
both auditory and visual learners.

Overall, the preceding review of related research reveals different trends in the findings about vocabulary learning strategies. Furthermore, some strategies are revealed to be more used or preferred by participants of different studies.

\section{Methodology}

\subsection{Participants}

The participants in this study were 20 male and 23 female Congolese learners of English in the Congolese educational system. They were recruited from grades 11 and 12 at a high school in the Brazzaville area of Southern Congo. The participants in the present study had a unique linguistic background since they were all speakers of two or more first languages. Specifically, all participants were speakers of French as the official and first language of instruction at school. In addition, they were also speakers of Kituba and/or Lingala, the two national languages of Congo.

\subsection{Research Questions}

1. What are the most frequent vocabulary learning strategies that are reinforced in the classroom?

2. What are the most frequent vocabulary learning strategies that students use?

3. Is there a relationship between strategies encouraged by the teachers and strategies used by the learners?

4. What vocabulary learning strategies do learners actually use to remember word meanings, learn how to use words and phrases in sentences, and learn how to pronounce words? Are these strategies acquired through classroom instruction or independently?

\subsection{Research Instrument}

A questionnaire including four parts was designed to collect data. Part One was designed to collect demographic information. Part Two included four open-ended questions that required short written answers. In Part Three, respondents were asked to indicate the relative frequency with which their English teachers have encouraged them to use different vocabulary learning strategies. Part Four included the same questions as Part Three, but the focus this time was moved from the teacher to the students themselves as they were asked to indicate the relative frequency with which they were using specific vocabulary learning strategies. Both Part Three and Four were given in the form of Likert-scale statements on a 4 point scale of $1=$ never, 2 = rarely, $3=$ sometimes, and $4=$ regularly. Each vocabulary learning strategy was described in a statement, and when necessary, illustrated by an example.

The validity of the survey was established by three specialists in TESOL and Applied Linguistics from a Midwestern university, who provided their critical judgments about the items included in the survey. 


\subsection{Variables and Scales of Measurement}

Each strategy was analyzed separately and thus constituted a separate variable with its own frequency distribution and a mean score. Each strategy was measured by a four point scale: $1=$ never; 2 = rarely; $3=$ sometimes; $4=$ regularly. Regularly reinforced or used strategies would have a mean of between 3 and 4. Strategies which have never been reinforced or used would have a mean of 1 . Infrequently strategies would have a mean of between 1.1 and 1.99 and would be described as very rarely to rarely encouraged or used.

\subsection{Data Collection}

Before giving the questionnaire to participants, they were given clear explanations about the purpose of the study. Clarifications were provided that the data would be confidential and used only for this study; and that participation was voluntary. Participants could therefore decide to stop taking part in the study at any time. Upon receiving these details, participants then completed and returned a consent form before completing the questionnaire. The entire survey was completed in the same day for the two grades that were involved in the study.

\subsection{Data Analysis}

Two main methods of data analysis were employed, statistical and content analysis. The Likert scale data was analyzed through descriptive statistics, including measures of central tendency and frequencies. In addition, multiple dependent t-tests were conducted in order to establish possible relationships between the strategies reinforced by the teachers and the ones used by the students. To control for Type I error, the alpha level of .05 was divided by the number of comparisons. Specifically, five dependent sample t-tests were performed at alpha .0029 after Bonferroni adjustments for Type I error.

\section{Results}

An ordering was applied in order to identify the most frequently and the least frequently teacher-promoted and student-used strategies. Table 1 is a summary of the most and least encouraged and used strategies.

Table 1. Most and least teacher-encouraged and student-used vocabulary learning strategies

\begin{tabular}{|l|l|l|l|l|l|l|l|l|}
\cline { 2 - 9 } \multicolumn{1}{c|}{} & \multicolumn{4}{c|}{ Most encouraged strategies } & \multicolumn{3}{c|}{ Least encouraged strategies } \\
\cline { 2 - 10 } & Contextual guessing & \multicolumn{2}{|c|}{ Dictionary use } & \multicolumn{2}{c|}{ Pronunciation } & \multicolumn{2}{c|}{ Flashcards use } \\
\cline { 2 - 9 } & Mean & SD & Mean & SD & Mean & SD & Mean & SD \\
\hline Teacher-encouraged & 3.17 & .80 & 3.21 & 1.08 & 1.88 & 1.07 & 1.86 & 1.13 \\
\hline Student-used & 3.48 & .51 & 3.33 & 1.02 & 1.98 & 1.17 & 2.02 & 1.08 \\
\hline
\end{tabular}

The relationship between teacher-encouraged and student-used strategies also was determined. Since there was only one group of participants measured on two different tasks, there was consequently no real independent variable. Five dependent sample $t$-tests were performed at alpha .003 after Bonferroni adjustments for Type I error. In addition, effect size Cohen's $d$ was calculated for the five comparisons since recent approaches (Cumming, 2012) to statistical significance claim that effect size is a more valid measure of statistical significance 
than $p$-values. The formula for calculating Cohen's $d$ for dependent $t$-tests is Mean difference divided by Standard Deviation of the difference (Cohen, 1988).

The purpose of the t-tests was to find out whether there was a match or discrepancy between the strategies reinforced by teachers in class and students' actual use of strategies. In terms of statistical significance, in the case of discrepancies, the t-test comparisons would show significant differences in the mean frequencies of strategies encouraged by teachers and used by students. In the case of correspondence or match, the $t$-tests would yield non-significant differences.

Considering the $p$-values and the effect sizes, it becomes obvious that there was a consistent correspondence between the reported strategies encouraged by teachers and the strategies used by students. This evidence is provided by the lack of significant differences in the mean frequency scores and the low values of the effect sizes, ranging between .06 and .35, in view of Cohen's (1988) reference values of .2, .5, and .8 for small, medium and large effects. The value of the highest effect size (contextual guessing strategy) $d=.35$ falls, according to Cohen (1988), on the scale between small and medium and provides further confirmatory evidence about the lack of significance according to the adjusted alpha level of .0029. The remaining four reported vocabulary learning strategies showed strong correspondence between teacher encouraged and student used strategies with $p$-values higher than .05 and small effect size values. The results of the 5 t-tests are summarized in Table 2.

With the exception of the monolingual dictionary which was slightly more frequently reinforced by teachers $($ Mean $=2.60)$ than used by students $($ Mean $=2.51), t(42)=.481, p$ $=.633$, Cohen's $d=.07$, the other four reported strategies were slightly more used by students than they were encouraged by teachers.

Table 2. Results of the $t$-test comparisons between encouraged and used strategies

\begin{tabular}{|c|c|c|c|c|c|c|c|c|}
\hline Vocabulary learning strategies & Tasks & $\mathrm{N}$ & Mean & $\mathrm{SD}$ & $t$ & df & $\begin{array}{l}\text { Sig. } \\
(2-t)\end{array}$ & $\begin{array}{l}\text { Eff. } \\
\text { Size } d\end{array}$ \\
\hline \multirow{2}{*}{1 - Contextual guessing } & Teacher-encouraged & 40 & 3.18 & 0.81 & \multirow{2}{*}{-2.223} & \multirow{2}{*}{39} & \multirow{2}{*}{$.032 *$} & \multirow{2}{*}{.35} \\
\hline & Student-used & 40 & 3.48 & 0.51 & & & & \\
\hline \multirow{2}{*}{2 - Bilingual dictionary use } & Teacher-encouraged & 43 & 3.21 & 1.08 & \multirow{2}{*}{-.710} & \multirow{2}{*}{42} & \multirow{2}{*}{.482} & \multirow{2}{*}{.11} \\
\hline & Student-used & 43 & 3.33 & 1.02 & & & & \\
\hline \multirow{2}{*}{3 - Monolingual dictionary use } & Teacher-encouraged & 43 & 2.60 & 1.03 & \multirow{2}{*}{.481} & \multirow{2}{*}{42} & \multirow{2}{*}{.633} & \multirow{2}{*}{.07} \\
\hline & Student-used & 43 & 2.51 & 1.08 & & & & \\
\hline \multirow{2}{*}{4 - Flashcards use } & Teacher-encouraged & 43 & 1.86 & 1.13 & \multirow{2}{*}{-.961} & \multirow{2}{*}{42} & \multirow{2}{*}{.342} & \multirow{2}{*}{.15} \\
\hline & Student-used & 43 & 2.02 & 1.08 & & & & \\
\hline \multirow{2}{*}{5 - Pronunciation check } & Teacher-encouraged & 41 & 1.90 & 1.09 & \multirow{2}{*}{-.363} & \multirow{2}{*}{40} & \multirow{2}{*}{.719} & \multirow{2}{*}{.06} \\
\hline & Student-used & 41 & 1.98 & 1.17 & & & & \\
\hline
\end{tabular}

Note: $*$ could be significant at alpha $=.05$, but not at alpha $=.0029$

Regarding the use of the strategies that students used the most, the analysis of the data revealed that the majority of participants recognized the role of their teachers in the acquisition of strategic competence. As shown in Table 3 below, 52.38\% $(\mathrm{N}=22)$ of the 
participants attributed the strategies they use to learn vocabulary to their teachers' practices and advice. For example, a male participant (S17) from the 11th grade stated, "Yes, it's our teachers who encourage us to use strategies." Another male participant (S20) from the 12th grade provided a rather detailed explanation: "Well, to tell the truth, it's English teachers who have taught and encouraged me to use all the strategies that I just mentioned."

Participants who claimed that they learned their strategies independently constituted $38.10 \%$ $(\mathrm{N}=16)$ of the overall 43 subjects. As an example, a 12th-grade male participant (S37) wrote: "I learned strategies by myself." One female independent learner participant (S8) from the 11th grade elaborated on her own process: "No, not at all. I personally learned strategies such as "when the teacher pronounces a new word that I have never heard, I must write it on the side [margin of the notebook] so that at home I can consult a dictionary and check its meaning'."

Three of the participants, constituting 7.14\% $(\mathrm{N}=3)$, recognized both their teachers' and their own role in strategy use. Finally, one male 12th-grade participant (S34) provided an interesting but irrelevant response which was coded in a separate category named 'unrelated'. It is not clear how the following quote relates to the question of teacher-encouraged or student own-acquired strategies: "In other words, we can say that English is the second most spoken language all over the world and one of the most spoken languages." It rather comments on the status of English around the world.

Table 3. Teacher-encouraged learning versus student-independently learning grouping

\begin{tabular}{|l|l|l|}
\hline Respondent categories & $\mathrm{N}$ & $\%$ \\
\hline Teacher-encouraged learning & 22 & 52.38 \\
\hline Student-independent learning & 16 & 38.10 \\
\hline Mixed learning & 3 & 7.14 \\
\hline Unrelated & 1 & 2.38 \\
\hline
\end{tabular}

\section{Discussion}

This section discusses the most and least encouraged and used vocabulary learning strategies whose results have been presented in the previous section. For this purpose, the results were put into thematic sections in view of theory and previous empirical research rather than discussed on a question-by-question basis to follow the order in which the research questions were posed in the methodology section.

\subsection{Vocabulary Learning and Contextual Guessing}

The quantitative results revealed that contextual guessing was the most student-used strategy with a Mean of 3.48 out of a maximum possible score of 4.00 . A possible explanation could be that students might have received substantial formal schema or language input and had developed the ability to use top-down strategies to comprehend English words and phrases in context. In the Congolese educational system, students begin learning the English language in the 6th grade. This means that the students who participated in the study were normally at their sixth or seventh year of learning English, at least in the educational context. 
The finding that participants used contextual guessing more than any other strategy is in line with Nation's (1990) conclusions that during interaction with a passage learners can guess at least eighty percent of unknown words from context.

\subsection{Contextual Guessing and Dictionary Use}

Though it was neither required nor clearly identified what the participants exactly based their guessing on, dictionary use and contextual guessing were two strategies that showed high frequencies of teacher encouragement; specifically, with their respective Means of 3.21 and 3.17. The two strategies were also identified as the most frequently student-used strategies with the highest Mean of 3.48 for contextual guessing and a Mean of 3.33 for dictionary use. Despite the lack of evidence for a direct link between these two strategies, it can be presumed that guessing and dictionary use were related in that participants regularly referred to dictionaries, especially bilingual dictionaries, to ensure that their guesses matched the real meaning of words and phrases they encountered in context. Dictionary consultation and contextual guessing were also identified by Mokhtar, Rawian, and Fauzee (2013) as the most preferred vocabulary learning strategies among the Net Generation students ("students who consider computers a natural part of their environment.” Mokhtar, Rawian, \& Fauzee, 2013, p. 9).

This is in line with Nation's (1990) view that guessing words from context is a useful strategy but that it should be followed by verifying meanings with a dictionary in order for learners to build and deepen their vocabulary knowledge. Without checking their guesses, learners may internalize incorrect meanings for the words and phrases they have guessed from context. Furthermore, it should also be mentioned here that it cannot be inferred that a second language learner has actually learned a new word simply by guessing an unknown word's meaning from context (Oxford \& Crookall, 1990). In a reading task for instance, learners may skip unfamiliar words if they get the meaning of the entire sentence from some potential contextual clues.

\subsection{Preferences for Bilingual versus Monolingual Dictionaries}

The encouragement and use of both monolingual and bilingual dictionaries were investigated in this study; however, of the two, bilingual dictionaries were the most frequently reinforced $($ Mean $=3.21)$ and employed $($ Mean $=3.33)$ strategies, whereas monolingual dictionaries were only moderately promoted (Mean $=2.60$ ) and used (Mean $=2.51$ ). A possible explanation for the preference for bilingual dictionaries could be that the study was conducted in an EFL context and that bilingual dictionaries provide the direct translation of words that students want to understand, whereas monolingual dictionaries explain words by the use of other English words that might be even more complicated than the target word. Another possible reason could be related to the cost and availability of dictionaries. Congo is a French-speaking country, and it is easier to find French-English bilingual dictionaries than English monolingual dictionaries.

The finding that bilingual dictionaries are preferred by EFL learners over monolingual dictionaries is consistent with previous findings. Bensoussan, Sim, and Weiss (1984) found 
that more than $59 \%$ of their subjects chose bilingual dictionaries and approximately $20 \%$ chose monolingual dictionaries.

The present study also offers supportive evidence for Ibrahim's (2012) findings about teachers' and students' views of dictionary use in an EFL context. Despite some discrepancies between teachers' and students' responses in his study, the results revealed that teachers encouraged students to use more bilingual than monolingual dictionaries, and likewise students showed preference for bilingual dictionaries.

\subsection{Vocabulary Learning and Pronunciation}

The quantitative data of the present study revealed that pronunciation was the least frequently used strategy.

A possible explanation for the rare use of pronunciation strategy could be that students might only need to be fluent and intelligible without any ambitions to sound native-like. This phenomenon can also be observed in Tergujeff's (2013) study on Finnish high school students. Tergujeff's study revealed fluency and intelligibility in English to be the major goals of most participants. Her participants' viewpoints were illustrated by quotes such as, "I often slip into a kind of Finnish English, awkward-sounding, but I would like to be fluent. It doesn't matter whether it's British or American, as long as it's genuinely intelligible and fluent" (p 84).

Another reason for students not to give frequent attention to pronunciation might be that it is not given sufficient attention and not practiced in class as students in the present study generally used the strategies which were reinforced by their teachers. This speculation is also in support of the findings of Tergujeff's (2013) study with Finnish high school English learners where participants indicated that pronunciation practice was not emphasized sufficiently.

Pronunciation difficulty in vocabulary learning and teaching could also be one of the reasons for teachers and learners to not regularly emphasize pronunciation. This hypothesis is in line with Wu's (2014) findings that pronunciation was perceived as the second most difficult aspect of English teaching and learning after vocabulary abstractness.

From the qualitative data of the present study, it becomes apparent that participants worked on their pronunciation independently through dictionary checks. As for teachers, they might neglect or even avoid focusing on pronunciation for a number of reasons, such as the lack of necessary tools to teach pronunciation and the lack of confidence due to their own insufficient exposure to English.

In the framework of the present study, only one participant $(2.33 \%)$ had stayed for a year in an African English-speaking country, Ghana, and none had stayed in a country where English is the native language. From the participants' lack of stay in countries where English is a native language, it could be extrapolated that it is very uncommon for English language learners and teachers in Congo to have stayed in an English-speaking country or a country where English is a native language. 


\subsection{Vocabulary Learning and Flashcards}

The present study revealed that teachers rarely promoted flashcards (Mean $=1.86)$. Students also used them low-moderately (Mean $=2.02$ ), only very slightly beyond the 'rarely' frequency scale. This finding is inconsistent with Al-Shuwairekh's (2001) finding that using flashcards is an effective strategy for both auditory and visual learners; but it is in line with Sariçoban and Saricaoglu's (2008) finding that flashcards were one among the strategies that students used the least to remember words meaning.

Given that participants in this study were more encouraged and inclined to guess words from context and then consult dictionaries to check the meaning of words, a possible reason for the participants to not frequently use flashcards could be the decontextualized nature of flashcards. Oxford and Crookall (1990) who identified flashcards as one of the most frequently used vocabulary learning strategies also recognized that flashcards use is a limited strategy unless some contextualizing embellishments are added by writing complete and meaningful sentences on flashcards.

Another potential reason could be that students also used notebooks and notepads, which are similar to self-created flashcards since they all consist in writing, reading, and revising. The following is a sample of quotes from participants in the present study, regarding their use of notepads and notebooks:

$\checkmark$ "First of all, I check or write the word in a notepad and then review and revise that word from time to time in order to remember." (S1)

$\checkmark$ "I write all these new words and phrases in my notepad and I often use them in my sentences." (S26)

$\checkmark$ "To remember the meaning of new words and phrases in English I do a small revision using my class notebook." (S28)

5.6 Relationship between Teacher-encouraged and Student-used Vocabulary Learning Strategies

The respondents' narrative comments corroborated the strong match between teacher-encouraged and student-used strategies. The following quotes effectively illustrate this trend: "Yes! It's my teachers who encourage [me to use vocabulary learning strategies]. And I practice at home to learn little by little" (S32), and "Well, to tell the truth, it's English teachers who have taught and encouraged me to use all the strategies that I just mentioned" (S20). This finding shows the important role of metacognitive awareness in vocabulary learning. Such awareness can be greatly attributed to the explicit reinforcement of effective vocabulary learning strategies by language teachers.

Further evidence for the important role of language teachers in developing students' metacognitive awareness of vocabulary learning strategies was provided by the fact that the least encouraged strategies (flashcards and pronunciation) also appeared to be the least used by students.

The obvious relationship between the most and least teacher-encouraged and student-used 
strategies corroborates the need for explicit instruction about vocabulary learning strategies as posited by Bornay (2011). In other words, through exposure and continuous practice learners can develop a repertoire of learning strategies that they find appropriate and effective for their learning styles and needs.

In a more specific way, the present study reveals that Congolese language teachers have consequently played an important role in reinforcing students' metacognitive awareness of vocabulary learning strategies. This finding could be explained by the fact that the study was conducted in an EFL context where the teacher can in some cases or for some learners be the main or even the only source of knowledge and language learning guidance. Students' dependence on and consideration of their teachers' guidance could be noticed in their interest to benefit from their teachers by paying attention to teachers' explanations, examples, and pronunciation, and by recording important teacher provided input in their notebooks and notepads. Such practices were described in participants' quotes, some of which are given below:

$\checkmark$ "When the teacher explains, I write down [new words and phrases] in a notepad." (S8)

$\checkmark$ "I often use sentences with these words that I write in my notepad." (S24)

$\checkmark$ "I do a small revision using my class notebook." (S28)

$\checkmark$ "I remember words from the examples that the teacher gives in class." (S20)

$\checkmark$ "I carefully listen to the teacher while he is speaking. I speak like him with his way of pronouncing. I follow all the movements of his mouth." (S20)

$\checkmark$ "I contact my English teacher [to learn how to pronounce difficult words]." (S26).

The above quotes reinforce both the teachers' role and the students' own initiative in the learning of new English vocabulary. Together they partake in the same process, complementing and facilitating each other. What students learn in class extends into their independent learning practices.

\section{Limitations and Recommendations}

While the present study provided insight into the vocabulary learning strategies of Congolese learners of English, it has some limitations that should be brought to the attention of researchers in the area of second language vocabulary learning. The first limitation is related to the small sample size. With a sample of 20 males and 23 females $(N=43)$, it would not be adequate to make generalizations about vocabulary learning strategies of all Congolese learners of English or learners from other educational and cultural environments. Moreover, the survey was administered to English language learners in an urban area, specifically in the capital city, Brazzaville. It can be postulated that English language learners from rural areas may use different strategies due to the differences in the learning contexts and opportunities. In view of these differences, future studies with Congolese learners of English should include 
mixed samples of urban and rural participants in order to find out if the learning environment influences the use of specific strategies.

Another limitation concerns the lack of evidence between strategy use and effectiveness. The present study did not include any test to examine students' success in vocabulary learning. In future studies, it would be important to correlate the student-used vocabulary learning strategies with vocabulary achievement scores.

In addition, the present study was carried out with students alone. Only their judgments were collected to assess both the frequency with which students thought teachers encouraged them to use strategies and the frequencies with which they used those strategies. It is recommended to work with the Congolese Ministry of Education through the modern languages section and involve teachers in future studies. Investigating teachers' opinions and practices in a direct way rather than through the viewpoints of students could provide more reliable data about what vocabulary learning strategies are emphasized by teachers in their English language classrooms and the reasons why they consider these strategies important. In a study involving teachers and students, conducted by Ibrahim (2012) to explore teachers' and students' views of dictionary use in an EFL context for example, many discrepancies were observed between teachers' and students' responses. In the framework of the present study, teachers could, for example, be able to explain why pronunciation appeared to be the least used and next-to-least encouraged strategy.

\section{Conclusion}

The present study has yielded insight into the use of vocabulary learning strategies by Congolese EFL learners. Overall, it can be concluded that Congolese EFL learners are aware of their own vocabulary learning strategies and practices which they employ both in and outside of class. Among them, contextual guessing and dictionary use were the most frequently used strategies, whereas pronunciation was the least frequently used.

However, strategy use alone is not sufficient to estimate the effectiveness for students' learning. Supplementing this research with data related to students' actual vocabulary knowledge would provide further insight into the connection between the use of particular strategies and the respective learning outcomes. Establishing such relationships would be of great help to Congolese EFL teachers as to which particular strategies they should encourage in order to obtain specific learning outcomes.

\section{Acknowledgement}

Special thanks to Dr. James Berry, Dr. Laura Halliday, and Rachel Israel, Southern Illinois University Carbondale. 


\section{References}

Al-Shuwairekh, S. (2001). Vocabulary learning strategies used by AFL (Arabic as Foreign Language) learners in Saudi Arabia. University of Leeds.

Benjamin, A., Jago, C., Kolln, M., Noden, H. R., Patterson, N., Penha, J., Smith, M. W.,

Wilhelm, J. D., Weaver, C., \& Wheeler, R. S. (2006). Teacher to teacher: What is your

most compelling reason for teaching grammar? The English Journal, 95, 5, 18-21. http://dx.doi.org/10.2307/30046583

Bensoussan, M., Sim, D., \& Weiss, R. (1984). The effect of dictionary usage on EFL test performance compared with student and teacher attitudes and expectations. Reading in a Foreign Language, 2, 2, 262-276.

Bornay, N. (2011). Explicit strategy training in vocabulary learning for beginning Spanish students. Flinders University Languages Online Review, 4, 3, 19-31.

Nirattisai, S., \& Chiramanee, T. (2014). Vocabulary learning strategies of Thai university students and its relationship to vocabulary size. International Journal of English Language Education, 2, 1, 273-287. http://dx.doi.org/10.5296/ijele.v2i1.5366

Cohen, J. (1988). Statistical power analysis of the behavioral sciences $\left(2^{\text {nd }}\right.$ ed.). Hillsdale, NJ: Lawrence and Erlbaum Associates.

Cumming, G. (2012). Understanding the new statistics: Effect sizes, confidence intervals and meta-Analysis. New York: Routledge.

Fan, M. Y. (2003). Frequency of use, perceived usefulness, and actual usefulness of second language vocabulary strategies: A study of Hong Kong learners. The Modern Language Journal, 87, 2, 222-241. http://dx.doi.org/10.1111/1540-4781.00187

Fraser, H. (2000). Coordinating improvements in pronunciation teaching for adult learners of

English as a second language. Canberra: DETYA (Australia National Training Authority Adult Literacy Project).

Fuentes, E. J. (1976). An investigation into the use of imagery and generativity in learning a foreign language vocabulary. Stanford University. Dissertation Abstracts International, 37, 5A, 2694.

Ghazal, L. (2007). Learning vocabulary in EFL contexts through vocabulary learning strategies. Novitas-Royal, 1, 2, 84-91.

Gilakjani, A. P. (2011). A study on the situation of pronunciation instruction in ESL/EFL classrooms. Journal of Studies in Education, 1, 1, 1-15.

Gilakjani, A. P. (2012). A study of factors affecting EFL learners' English pronunciation learning and the strategies for instruction. International Journal of Humanities and Social 
Science, 2, 3, 119-128.

Huang, S., \& Eslami, Z. (2013). The use of dictionary and contextual guessing strategies for vocabulary learning by advanced English language learners. English Language and Literature Studies, 3, 3, 68-76. http://dx.doi.org/10.5539/ells.v3n3p1

Hulstijn, J. H. (1989). Implicit and incidental second language learning: Experiments in the processing of natural and partly artificial input. In H. W. Dechert \& M. Raupach (Eds.), Interlingual Processing (pp. 49-73). Tubingen Gunter Narr.

Ibrahim, H. A. (2012). Monolingual dictionary use in an EFL context. English Language Teaching, 5, 7, 2-7.

Kaivanpanah, S., \& Alavi, S. M. (2008). The role of linguistic knowledge in word meaning inferencing. System. 36, 2, 172-195. http://dx.doi.org/10.1016/j.system.2007.10.006

Kornell, N. (2009). Optimising learning using flashcards: spacing is more effective than cramming. Applied Cognitive Psychology, 23, 1297-1317. http://dx.doi.org/10.1002/acp.1537

Lawson, M. J., \& Hogben, D. (1996). The vocabulary learning strategies of foreign-language students. Language Learning, 46, 1, 101-135. http://dx.doi.org/10.1111/j.1467-1770.1996.tb00642.x

Luppescu, S., \& Day, R. (1993). Reading, dictionaries, and vocabulary learning. Language Learning, 43, 2, 263-287. http://dx.doi.org/10.1111/j.1467-1770.1992.tb00717.x

Mokhtar, A. A., Rawian, R. M., \& Fauzee, M. S. O. (2013). The role of dictionary strategy in passive vocabulary knowledge acquisition of net generation students. Journal for the Study of English Linguistics, 1, 1, 8-20. http://dx.doi.org/10.5296/jsel.v1i1.4444

Nation, I. S. P. (1990). Teaching and learning vocabulary. Boston: Heinle \& Heinle.

Oxford, R., \& Crookall, D. (1990).Vocabulary learning: a critical analysis of techniques. TESL Canada Journal, 7, 2, 9-30.

Oxford, R. L. , \& Scarcella, R. C. (1994). Second language vocabulary learning among adults: state of the art in vocabulary instruction. System, 22, 231-243. http://dx.doi.org/10.1016/0346-251X(94)90059-0

Prichard, C. (2008). Evaluating L2 readers' vocabulary strategies and dictionary use. Reading in a Foreign Language, 20, 2, 216-231.

Sariçoban, A., \& Saricaoglu, A. (2008). The effect of the relationship between learning and teaching strategies on academic achievement. Novitas-Royal, 2, 2, 162-175.

Sultana, F. (2014). Efficacy of outside - classroom English language learning: a study of intermediate Bengali medium students studying English at tertiary level in Bangladesh. International Journal of English Language Education, 2, 2, 28-35. http://dx.doi.org/10.5296/ijele.v2i2.5699 
Tergujeff, E. (2013). Learner perspective on English pronunciation teaching in an EFL context Research in Language, 11, 1, 82-95.

Wu, L. (2014). Technical college students' perceptions of English for specific purposes vocabulary learning and teaching. International Journal of English Language Education, 2, 1, 176-186. http://dx.doi.org/10.5296/ijele.v2i1.4987

Yu, S. (2000). Understanding the use of vocabulary learning strategies from socio-cultural perspectives: a comparative study of Japanese, Korean, and Taiwanese EFL learners. National Chiayi University, Taiwan.

\section{Appendix}

Appendix 1. Survey Questionnaire

\section{Section One}

\section{Demographic Information}

Check the right option or write the answer:
1) Gender:
Male
Female

2) Age Group: $18-20$

3) Class:

4) Name of your school:

5) How long have you studied English?

6) Have you lived in an English speaking country such as England, the USA, Canada, etc.?
Yes $\square$
No $\square$

7) If you answered "Yes" in question 6, please write in which country and for how long

8) Except school, what other sources do you use to learn English? Check all that are true for you:

a) Private lessons in the English language $\square$

b) Watching English language movies

c) Listening to English language songs

d) Using the internet in the English language

e) Playing computer games in the English language

f) Communicating with native speakers of English

g) Others (Please list them in the provided space)

9) Name the Congolese languages that you speak fluently (eg: Kituba, Lari, ...):

\section{Section Two}

\section{Short answer questions}

Q1: What strategies do you use to help you remember the meaning of new words and phrases in English? Describe the ones that are the most effective for you. 
Q2: What strategies do you use to help you learn how to use new English words and phrases in a sentence? Describe the ones that are the most effective for you.

Q3: What strategies do you use to help you learn how to pronounce new words and phrases in English? Describe the ones that are the most effective for you.

Q4: Are the strategies you use to learn vocabulary encouraged by your English teachers or have you learned them on your own? Please explain briefly.

\section{Section Three}

\section{Your English Teacher(s)}

Please, indicate the relative frequency with which your English teachers have encouraged you to use the following vocabulary learning strategies:

$$
1=\text { Never; } \quad 2 \text { = Rarely; } \quad 3 \text { = Sometimes; } \quad 4 \text { = Regularly }
$$

\section{My English teacher(s) encourage(s) us to ...}

1. Use a bilingual dictionary (English-French or FrenchEnglish) to check the meaning of unknown words.

2. Use a monolingual dictionary (English - English) to check the meaning of unknown words.

3. Use an online dictionary or an audio dictionary to check the pronunciation of new/difficult English words.

4. Use a glossary at the end of a text or a book to check the meaning of new/difficult words found in a text/book.

5. Try to understand the meaning of new words from the context.

6. Pay attention to the meaning of prefixes. For example, the prefix 'un-' when attached to a word usually negates the word $(u n=n o t)$. So, the word (adjective) unhappy means not happy.

7. Pay attention to the meaning of suffixes. For instance, the suffix '-er' usually means "one who does something”. 
Examples: teach - teacher; write - writer; read - reader.

8. Pay attention to the meaning of words' roots. For example, the word animation is formed from the Latin root 'anim' which means life.

9. Learn the synonyms (words that have similar meanings) of new words that we study in class.

My English teacher(s) encourage(s) us to ...

10. Learn the antonyms (words with opposite meanings) of new words that we study in class.

11. Remember words by writing them several times.

12. Intentionally try to use words we have learned when we speak or write to make sure that we practice them.

13. Create flash cards (hard copy or electronic) with the new word on one side, its definition and example sentence on the other, and then use the cards to test ourselves and revise our knowledge of the words.

14. Make sure that we know how to use new words in a sentence.

15. Learn and practice the most frequent words that occur with the new word. For example: 'handsome' commonly occurs with 'man'.

16. Connect French-English cognates like family and famille or identical words like table and table.

17. Connect words by associating familiar with unfamiliar words through personal images and/or sounds. For example, to learn the English new word 'home', we can link it to the French word 'homme' which sounds a bit like 'home' (maison). 


\section{Section Four}

\section{Strategies used by you}

Please, indicate the relative frequency with which you use the following vocabulary learning strategies:

$1=$ Never;

$2=$ Rarely;

$3=$ Sometimes;

1. I use a bilingual dictionary (English-French or French-English) to check the meaning of unknown words.

2. I use a monolingual dictionary (English - English) to check the meaning of unknown words.

3. I use an online dictionary or an audio dictionary to check the pronunciation of new/difficult English words.

4. Whenever I find a new/difficult word in a text or a book, I use a glossary at the end of a text or a book to check the meaning of new/difficult words found in a text/book.

5. When I find a new word in a text, I try to understand the meaning of that word from the context.

6. To learn new words, I pay attention to the meaning of prefixes. For example, the prefix ' $u n$-' when attached to a word usually negates the word ( $u n=n o t)$. So, the word (adjective) unhappy means not happy.

7. To learn new words, I pay attention to the meaning of suffixes. For instance, the suffix '-er' usually means "one who does something". Examples: teach - teacher; write - writer; read - reader.

8. I pay attention to the meaning of words' roots. For example, the word animation is formed from the Latin root 'anim' which means life.

9. When I learn new words, I also learn their synonyms (words that have similar meanings). 
10. When I learn new words, I also learn their antonyms (words that have opposite meanings).

11. I remember words by writing them several times.

12. To make sure that I remember words, I intentionally try to use them when I speak or write in English.

13. I create my own flash cards with the word on one side, its definition and example sentence on the other, and then use the card to test myself and revise my knowledge of the word.

14. When I learn a new word, I make sure that I know how to use the word in a sentence.

15. When I learn a new word, I also learn and practice the most frequent words that occur with the new word. For example: 'handsome' commonly occurs with 'man'.

16. I connect French-English cognates like family and famille or identical words like table and table.

17. To learn a new word, I connect words by associating familiar with unfamiliar words through personal images and/or sounds. For example, to learn the English new word 'home', I can link it to the French word 'homme' which sounds a bit like 'home' (maison).

This is the end of the survey. Thank you for your time.

\section{Copyright Disclaimer}

Copyright for this article is retained by the author(s), with first publication rights granted to the journal.

This is an open-access article distributed under the terms and conditions of the Creative Commons Attribution license (http://creativecommons.org/licenses/by/3.0/). 